\title{
동해에서 돌연고파의 기준 제안 \\ A Proposal for Criterion of Sudden High Waves in the East Sea
}

\author{
김인철* · 오지희* • 서경덕* \\ In-Chul Kim*, Jihee Oh* and Kyung-Duck Suh*
}

\begin{abstract}
요 지 : 동해에서 주로 겨울철에 발생하며 파고가 크고 주기가 긴 너울성 고파의 주요 특성 중 하나는 잔잔한 상 태에서 갑자기 파가 커지는 돌발성이다. 본 연구에서는 이러한 돌발성을 나타내기 위하여 돌연고파라는 용어를 도 입하였다. 돌연고파의 기준을 제안하기 위하여 강릉과 왕돌초에서 2005년부터 8년간 관측된 파랑자료와 같은 기간 동안 강원도와 경상북도 연안에서 발생했던 해상 사고 기록을 비교하였다. 그 결과 $\Delta\left(H^{2} L\right) / \Delta t$ 가 상위 $20 \%$ 값 인 $88.6 \mathrm{~m}^{3} / \mathrm{hr}$ 이상일 때 대부분의 사고 기록과 일치하는 것으로 나타나 이를 돌연고파의 기준으로 제안하였다. 사 용된 변수는 한 파장당 파랑 에너지의 단위시간당 증가율을 나타내며, 고파의 파고 및 주기뿐만 아니라 돌발성도 포함한다.
\end{abstract}

핵심용어 : 너울성 고파, 돌발성, 돌연고파, 동해, 해상 사고

\begin{abstract}
One of the major characteristics of the swell-like high waves, which occur in the East Sea mostly in winter with large height and long period, is its suddenness associated with the rapid development of high waves from a calm state of sea. To represent such suddenness, in this study, the term sudden high waves is introduced. To propose the criterion of sudden high waves, comparisons were made between the wave measurement data at Gangneung and Wangdolcho for eight years from 2005 and the record of marine accidents and property damage on the coast of Gangwon-do Province and Gyeongsangbuk-do Province during the same period. It was found that most of the accidents occurred when $\Delta\left(H^{2} L\right) / \Delta t$ was approximately greater than the top $20 \%$ or $88.6 \mathrm{~m}^{3} / \mathrm{hr}$, which is therefore proposed as the criterion of sudden high waves. The used variable represents the rate of increase of the wave energy in one wavelength, including not only height and period but also suddenness of high waves.
\end{abstract}

Keywords : swell-like high waves, suddenness, sudden high waves, East Sea, marine accident

\section{1. 서 론}

최근 십여 년 동안 우리나라 동해안에서 갑작스러운 큰 파 로 인한 사고가 빈번하게 발생하고 있다. 이는 주로 10 월에 서 이듬해 2 월 사이의 겨울철에 반복적으로 발생하는데, 중 국 내륙 및 우리나라 부근에서 강하게 발달한 온대성 저기압 이 동해안 부근으로 접근해 올 때 발생한 폭풍파가 내습하게 됨에 따라 발생하는 것으로 알려져 있다(정 등, 2007, 2008). 그런데 이 고파가 발생할 때의 날씨는 좋은 경우가 대부분이 라 고파에 대한 대비가 부족하여 많은 인명피해와 재산피해 를 야기하고 있다(오 등, 2010). 2005년 이후 동해안에서 고 파의 발생으로 인한 해상 및 해안에서의 사상자는 집계된 것 만 45명에 달하며, 재산 피해는 연평균 백억 원을 상회한다( 정과 오, 2009). 이러한 고파를 일본에서는 'Yorimawarinami'라는 용어로 부르는데(Nagai et al., 2009; Lee et al., 2010), Nagai et al.(2009)은 이를 'sudden peculiar long period swell'이라고 표현하였다.
이 고파는 너울에 비해서 파랑 주파수 스펙트럼의 폭이 넓 으며, 유의파고가 $5 \mathrm{~m}$ 이상인 경우가 빈번하다. 또한 9초 이 상의 긴 첨두주기를 갖는데, 이는 통상의 풍파 수준을 상회 하는 수치이다. 이러한 이유로 인하여 이 고파는 너울 또는 풍파로 정의하기 다소 힘든 점이 있다(오 등, 2010). 오 등 (2010)은 이러한 점을 고려하여 유의주기가 길고 $\left(T_{s} \geq 9 \mathrm{~s}\right)$ 유 의파고가 큰 $\left(H_{s} \geq 3 \mathrm{~m}\right)$ 파랑을 너울성 고파라고 지칭하였다. 그 러나 기존의 너울성 고파라는 명칭은 현상의 돌발성 (suddenness)을 적절히 나타내지 못하는 용어라 생각하여, 본 연구에서는 돌연고파(sudden high wave)로 현상을 지칭하였다.

한편 너울성 고파에 대한 기존의 기준은 임의성이 다소 짙 어, 더 많은 연구를 통하여 명확히 정의될 필요성이 있다(오 등, 2010). 또한, 이 기준을 돌연고파에 적용할 경우, 해수면 이 잔잔한 상태에서 고파가 발생할 때까지 걸리는 시간을 고 려하기 어려운 문제점이 있다.

돌연고파의 가장 중요한 특성 중 하나는 돌발성이다. 국지 적 강풍을 동반하지 않고 갑작스럽게 발생하는 돌연고파의 특

*서울대학교 건설환경공학부(Corresponding author: Kyung-Duck Suh, Department of Civil and Environmental Engineering, Seoul National University, 1 Gwanak-ro, Gwanak-gu, Seoul 08826, Korea, Tel:+82-2-880-8760, Fax:+82-2-873-2684, kdsuh@snu.ac.kr) 
성이 많은 인명피해와 재산피해를 야기하고 있다. 이런 돌발 성과 큰 파랑을 잘 나타내기 위해서는 변수 안에 두 가지 정 보가 포함되어야 한다. 첫 번째는 얼마나 짧은 시간 안에 돌 연고파가 발생하는 지에 대한 것이고, 두 번째는 돌연고파의 크기(파고 및 주기)가 얼마인 지에 대한 것이다. 본 연구의 목 적은 위의 두 정보가 포함된 변수를 도출하여 돌연고파에 대 한 기준을 제시하는 것이다. 이후 본 논문에서 사용되는 기호 중 파고 $(H)$, 주기 $(T)$, 파장 $(L)$ 은 모두 유의파에 대한 값이다. 다 음 장에서는 연구에 사용된 자료에 대하여 설명한다. 3 장에서 는 돌연고파 관련 이론을 기술하고, 4 장에서는 자료 분석을 통하여 돌연고파의 기준을 제안한다. 마지막으로 5 장에서 본 연구의 요약 및 주요 결론을 기술한다.

\section{2. 자 료}

본 연구에서는 한국해양과학기술원에서 제공하는 2005년 2월부터 2013년 2월까지의 강릉 및 왕돌초 지역의 겨울철 파 랑 관측자료와 2005년부터 2013년까지의 강원도 및 경상북 도 연안의 너울성 고파 발생 및 피해 자료를 비교, 분석하여 동해안에서 돌연고파로 인해 사고가 발생하였을 때의 파랑 특 성을 고찰하였다. 파랑 관측 자료는 Fig. 1 에 보이는 강릉과 왕돌초 인근에 위치한 지점에서 측정한 것이다. 관측기기가 위치한 지점의 수심은 각각 $15 \mathrm{~m}$ 와 $15.3 \mathrm{~m}$ 이고, 파랑 자료는 매 30 분마다 취득되었다.

\section{3. 이 론}

\section{1 돌연고파의 특성}

Fig. 2 및 3 는 각각 2005년 10월 $21 \sim 25$ 일, 2006년 10 월 $22 \sim 26$ 일에 강릉에서 관측된 유의파고와 유의주기의 시 계열을 나타낸 것이다. 두 시기 모두 돌연고파가 발생하여 많 은 인명피해와 재산피해를 야기한 대표 사례이다. 두 경우를

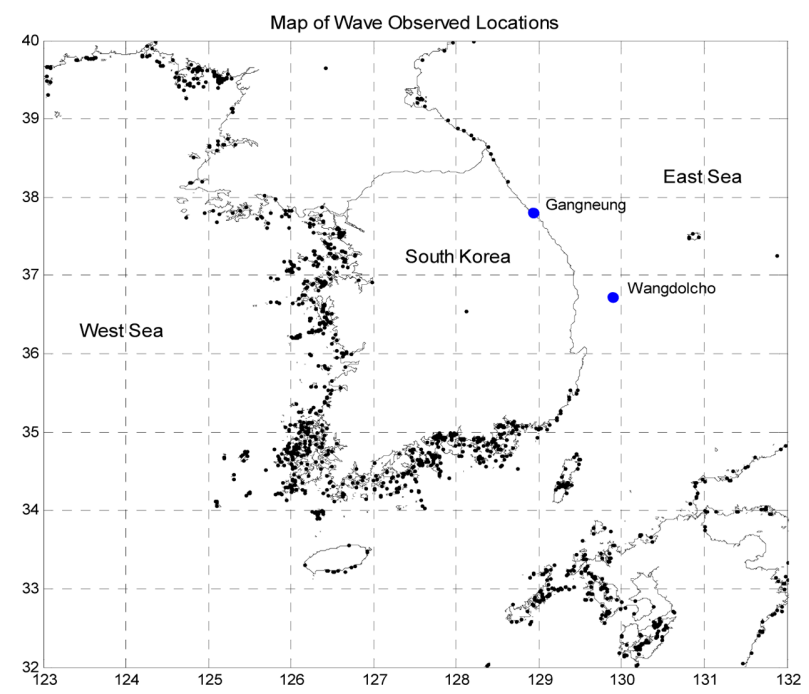

Fig. 1. Location of wave observation.
보면, 돌연고파가 발생하기 전에는 유의파고가 $1 \mathrm{~m}$ 미만, 유 의주기 6초 미만으로 잔잔한 상태였다가 갑작스럽게 유의파 고와 유의주기가 상승함을 알 수 있다. 즉, 돌연고파는 통상 의 너울에 비하여 유의파고가 크고, 통상의 풍파에 비하여 유 의주기가 길며, 국지적 강풍을 동반하지 않고 갑작스럽게 발 생하는 특성을 갖는다(오 등, 2010).

\section{2 고파 이벤트의 결정}

돌연고파의 기준을 제시하기 위해서는 우선 고파 이벤트에
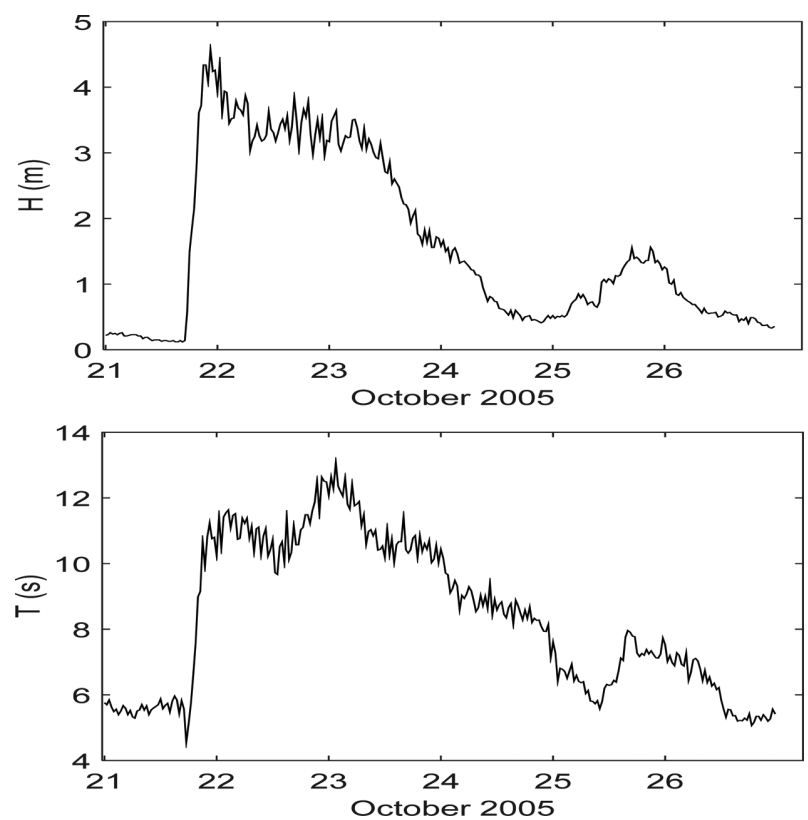

Fig. 2. Significant wave height and period during October 21-26, 2005 at Gangneung wave station.
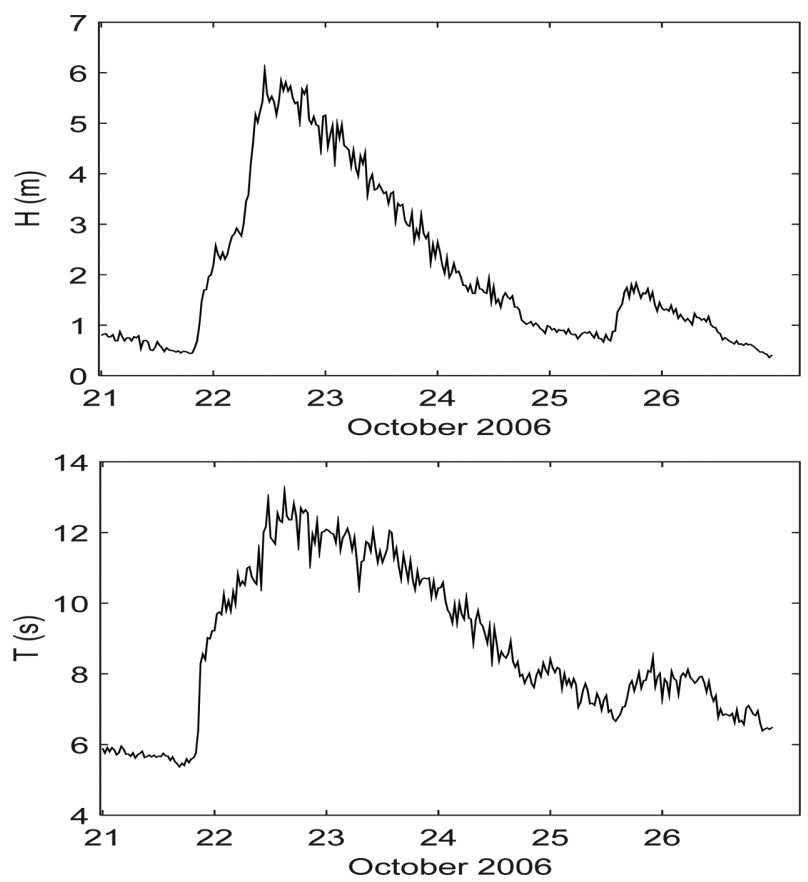

Fig. 3. Significant wave height and period during October 21-26, 2006 at Gangneung wave station. 
대한 결정이 선행되어야 한다. Figs. 2 및 3에서 보듯이 파 고와 주기는 거의 비례 관계에 있기 때문에 여기서는 파고의 시계열에 기초하여 고파 이벤트를 결정한다. 여기서 고파 이 벤트라 함은 해수면이 잔잔한 상태를 유지하다가 파고가 증 가하여 거친 상태가 되었다가 다시 잔잔한 상태로 되돌아올 때 까지를 일컫는다. Douglas sea scale의 Degree 3인 slight sea 는 파고가 $0.5 \sim 1.25 \mathrm{~m}$ 사이를 일컫는데(World of Earth Science, 2003), 본 연구에서는 이 단계를 잔잔한 해면의 기준 으로 삼아서 한 시점의 유의파고가 이 기준의 중간 값인 $(0.5+1.25) / 2=0.875 \mathrm{~m}$ 이하인 경우를 잔잔한 상태로 정의하였다. 고파 이벤트에 대한 결정은 다음 순서를 따른다. 설명을 위 하여 Fig. 4를 참고한다. 이 그림에서 역삼각형으로 표시된 시 점이 고파 이벤트의 시작 및 끝 점을 나타낸다. 그림에서 보 듯이 한 이벤트 동안에 파고의 변동이 매우 심한 것을 알 수 있다. 해수면이 잔잔한 상태에서 거친 상태가 되었다가 다시 잔잔한 상태로 되돌아오는 기준만을 가지고 고파 이벤트를 결 정하면 너무 많은 이벤트가 발생하는 것으로 계산되기 때문 에 최솟값 비교기간(Comparison period of minimum wave height)이라는 개념을 도입하였다. Fig. 4는 최솟값 비교기간 을 60 시간으로 설정했을 때의 결과이다. 임의의 한 시점에 서 파고가 잔잔한 상태 $(0.875 \mathrm{~m}$ 이하)를 만족시키면서 그 시 점으로부터 비교기간만큼의 전과 후 사이에서 최소가 될 경 우 그 점을 이벤트의 시작점으로 결정한다. 이러한 방법을 사 용하면 변동을 거듭하여 미분하기 힘든 그래프 내에서 극솟 값을 찾을 수 있다. 예를 들어 Fig. 4의 12일 21시쯤에 파고 가 $0.875 \mathrm{~m}$ 보다 작고 그 점으로부터 60 시간 전과 후 사이에 서 최소가 되기 때문에 이벤트의 시작점으로 선정되었다. 14 일 18 시쯤에도 파고가 $0.875 \mathrm{~m}$ 보다 작고 최솟값을 보이지만 그 점으로부터 60 시간 전 (즉 12일 6시) 이후에 그보다 작 은 파고가 발생하였기 때문에 새로운 이벤트의 시작점으로 선 정되지 않았다. 16 일 21시쯤과 17 일 18 시쯤의 점도 같은 이 유로 선정되지 않았다. 그 이후 파고가 계속 증가하여 $0.875 \mathrm{~m}$ 이상으로 유지되다가 24일 9시쯤에 $0.875 \mathrm{~m}$ 이하로 최솟값을 보이지만 그 점으로부터 60시간 후 (즉 26일 21시) 이전에 그보다 작은 파고가 발생하였기 때문에 이벤트의 시 작점으로 선정되지 않았다. 25 일 12 시쯤과 27 일 0 시쯤의 점

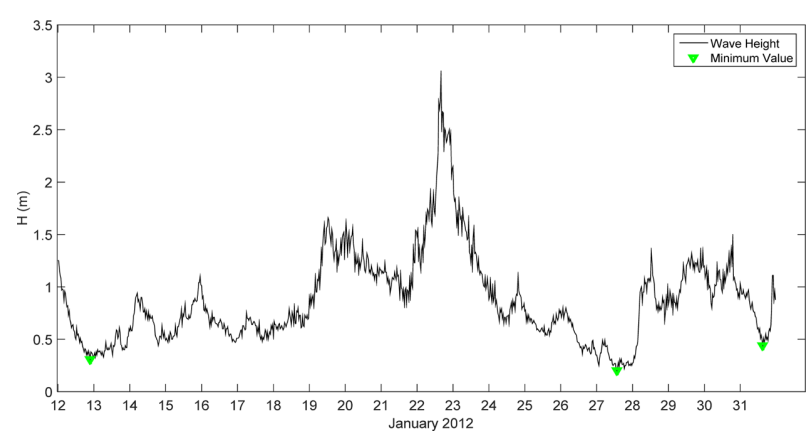

Fig. 4. Illustration of high wave event.
도 같은 이유로 선정되지 않았고, 27일 12 시쯤에 가서야 전 후 60 시간 이내에 그보다 더 작은 값이 없기 때문에 새로 운 이벤트의 시작점으로 선정되었다.

\section{3 돌연고파 강도 변수의 선정}

돌연고파를 나타내는 변수로 우선 생각할 수 있는 것은 파 고 $(H)$ 일 것이다. 파고는 파의 크기를 가장 잘 나타내며 파로 인한 피해에 가장 직접적인 영향을 주는 변수이다. 그러나 Figs. 2 및 3 에서 보듯이 돌연고파 발생 시에는 짧은 시간 동 안에 파고뿐만 아니라 주기 $(T)$ 도 급격히 증가한다. 그런데 파 의 주기가 증가하면 파장 $(L)$ 도 증가하기 때문에 파고와 주기 의 영향을 동시에 나타낼 수 있는 변수로 $H^{2} L$ 을 생각할 수 있을 것이다. 한 파장당 파랑 에너지를 $\rho g H^{2} L / 8$ 로 나타낼 수 있으므로 (여기서 $\rho=$ 해수의 밀도, $g=$ 중력가속도), $H^{2} L$ 은 파랑 에너지를 나타내는 변수로 간주할 수 있다. 참 고로 김과 이(2008)는 2008년 2월 23 24일 동해에 내습하여 큰 피해를 입혔던 파랑 자료를 웨이블릿 방법으로 분석하여 짧은 시간 동안에 파랑 에너지가 급격히 증가하는 것을 보인 바 있다. 또한 수심이 얕은 경우 파장은 주기뿐만 아니라 수 심의 영향도 받기 때문에 $H^{2} L$ 은 파고, 주기, 수심의 영향을 모두 포함한다. 돌연고파의 대표적인 특성 중 하나는 해수면 이 잔잔한 상태에서 갑자기 파고 및 주기가 증가하는 돌발성 이다. 이 돌발성을 나타내기 위해서는 잔잔한 상태에서 큰 파 랑으로 발전하는 데 걸리는 시간 $\Delta t$ 가 필요하다. 따라서 본 연구에서는 돌연고파의 강도를 나타내는 변수로 $\Delta H / \Delta t$ 와 $\Delta\left(H^{2} L\right) / \Delta t$ 를 선정하였다. 여기서 $\Delta H$ 와 $\Delta\left(H^{2} L\right)$ 은 각각 시간 $\Delta t$ 동안의 $H$ 와 $H^{2} L$ 의 증가량이다.

\section{4 돌연고파 강도 변수의 계산}

3.2절에서 결정한 하나의 고파 이벤트 내에서 $H$ 또는 $H^{2} L$ 이 최대가 되는 점을 이벤트 내의 최댓값으로 잡는다. 같 은 최댓값이 여러 개일 경우에는 먼저 나온 점으로 한다. 이 벤트의 시작점과 최댓값 발생 시점 사이에서 파고가 Douglas sea scale의 Degree 3인 slight sea의 상한 값인 $1.25 \mathrm{~m}$ 이하이 면서, $H$ 또는 $H^{2} L$ 의 값이 최댓값의 $1 / 10$ 이하가 되는 점들 중 최댓값과의 기울기 $\left(\Delta H / \Delta t\right.$ 또는 $\left.\Delta\left(H^{2} L\right) / \Delta t\right)$ 가 가장 큰 값을 갖는 점을 돌연고파의 시작점으로 채택하였다 (Fig. 5에 서 다이아몬드로 표시한 점). 같은 기울기 값을 갖는 점이 여 러 개일 경우 먼저 나온 점으로 하였다. Douglas sea scale의 Degree 3인 slight sea의 중간 값인 $0.875 \mathrm{~m}$ 는 고파 이벤트를 결정하기 위한 기준으로 사용되었는데, 돌연고파의 시작점의 기준으로는 다소 보수적이기 때문에 상한 값인 $1.25 \mathrm{~m}$ 를 기준 으로 하였다. 또한, 돌연고파 강도 변수의 급격한 증가가 돌연 고파의 돌발성에 중요한 요소이기 때문에 최댓값의 $1 / 10$ 이하 가 되는 점들을 돌연고파의 시작점의 후보로 간주하였다.

Fig. 5의 (a)와 (b)는 각각 2008년 2월 22 27일과 2009년 1월 6 12일에 강릉에서 관측된 $H^{2} L$ 시계열을 나타낸 것으 

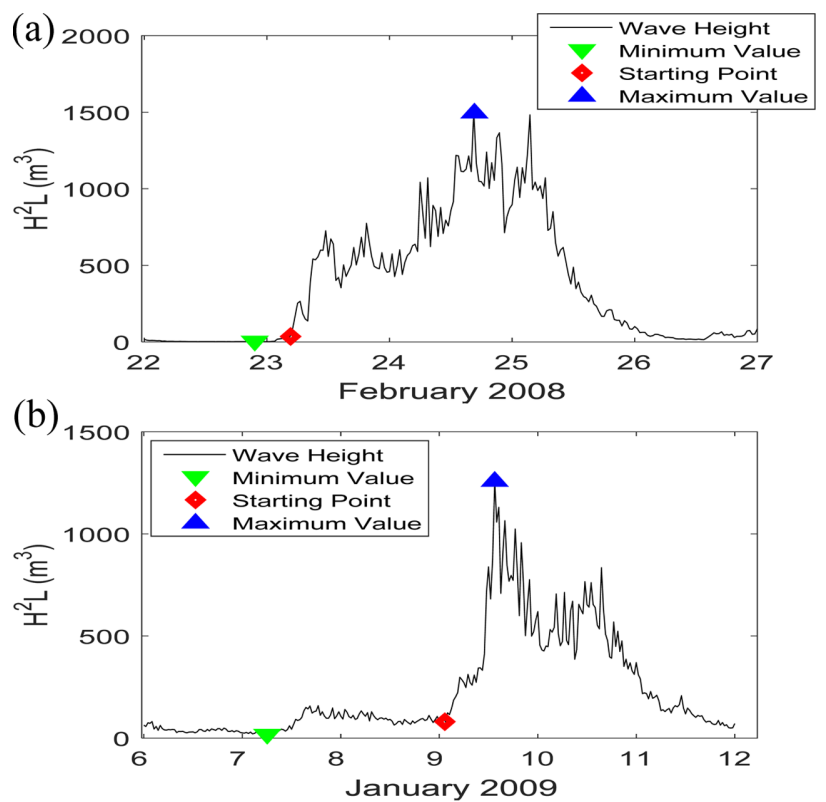

Fig. 5. Illustration of determination of intensity of sudden high waves.

로 두 기간 모두 각각 하나의 고파 이벤트가 결정되었다. 그 런데 두 그래프의 돌연고파 시작점들은 상당히 상이한 곳에 위치해 있음을 알 수 있다. 그 이유는 (a) 그래프의 경우, 최 댓값과의 기울기가 가장 큰 값을 갖는 점이 24 일과 25 일 사 이에 존재하지만, 이 기간 동안의 점들은 파고가 $1.25 \mathrm{~m}$ 이 하이면서, $H^{2} L$ 의 값이 최댓값의 $1 / 10$ 이하여야 한다는 돌연 고파 시작점의 기준을 만족하지 못하기 때문에 시작점이 되 지 못한다. 반면에 (b) 그래프의 경우에는, 9 일과 10 일 사이 의 한 점이 최댓값과의 기울기가 가장 큰 값을 나타내면서 돌 연고파 시작점의 기준을 만족시키기 때문에 시작점으로 결정 되었다. 따라서 두 이벤트를 비교해 보면 (b)가 (a)보다 더 큰 돌발성을 갖고 있음을 알 수 있고, (a)가 (b)보다 이벤트 내에 서 더 높은 최댓값을 갖고 있음에도 불구하고 $\Delta H^{2} L / \Delta t$ 값은 $40.7 \mathrm{~m}^{3} / \mathrm{hr}$ 으로 $98.2 \mathrm{~m}^{3} / \mathrm{hr}$ 인 (b)보다 작은 값을 갖는다. 즉, 단 순 고파가 높은 $H$ 또는 $H^{2} L$ 값을 갖고 있어도 (a)와 같이 돌 발성이 크지 않으면 돌연고파 강도 변수는 낮게 계산된다. 따 라서 위와 같은 돌연고파 강도 변수 계산 방법을 통하여 단 순 고파와 돌연고파를 구분할 수 있다.

\section{4. 결 과}

\section{1 최솟값 비교기간의 결정}

3.2절에서 설명한 고파 이벤트를 결정하기 위해서는 최솟 값 비교기간을 결정해야 한다. 적절한 최솟값 비교기간을 결 정하기 위해서 다음과 같은 방법을 사용하였다. 우선 임의로 설정한 최솟값 비교기간을 이용하여 3.2절에서 설명한 방법 으로 만들어지는 실제 이벤트 개수(number of actual events) 를 계산하였다. 다음으로 이 비교기간으로 만들 수 있는 최
Table 1. Values of number of actual events divided by number of maximum possible events in Gangneung depending on comparison period of minimum wave height.

\begin{tabular}{cc}
\hline \hline $\begin{array}{c}\text { Comparison period of } \\
\text { minimum wave height }(\mathrm{hr})\end{array}$ & $\begin{array}{c}\text { (Number of actual events) } \\
\text { /(Number of maximum } \\
\text { possible events) }\end{array}$ \\
\hline 12 & 0.479 \\
24 & 0.619 \\
36 & 0.731 \\
48 & 0.808 \\
55 & 0.821 \\
57.5 & 0.831 \\
60 & 0.835 \\
62.5 & 0.819 \\
65 & 0.807 \\
72 & 0.806 \\
\hline
\end{tabular}

대 이벤트 개수(number of maximum possible events)를 계 산하였다. 예를 들어서 비교기간을 60 시간으로 했을 경우 매 120 시간마다 하나의 이벤트가 발생한다고 간주하여 최대 이 벤트 개수는 전체 관측기간을 120 시간으로 나눈 값으로 계 산된다. 다음으로 최솟값 비교기간을 변화시켜 가면서 실제 이벤트 개수를 최대 이벤트 개수로 나눈 값이 1 에 가장 가 까워지는 경우를 찾아서 이를 최솟값 비교기간으로 결정하였 다. 강릉 지역의 파랑 관측자료에 대해 최솟값 비교기간을 12 시간부터 72 시간까지 조정해 본 결과는 Table 1과 같다. 따 라서 (실제 이벤트 개수)/(최대 이벤트 개수)가 1 에 가장 근 접한 비교기간인 60 시간을 최솟값 비교기간으로 결정하였다.

\section{2 돌연고파의 기준}

강릉 지역의 파랑 관측자료에 대해 최솟값 비교간격을 60 시간으로 하여 두 변수 $H$ 및 $H^{2} L$ 에 대하여 이벤트를 생성 한 결과, 각각 208 개와 206 개의 이벤트가 생성되었다. 이와 같 이 생성된 이벤트를 강원도 연안의 너울성 고파 발생 및 피 해 현황 자료와 비교해 보았다. Table 2는 2005년부터 2012 년까지 강원도와 경상북도 연안에서 겨울철(10월부터 이듬해 2월까지)에 발생한 해난 사고 및 피해 현황 자료이다. 한편 Table 3은 Table 2의 자료 중 강원도 연안의 사고 및 피해 발생 시기에 강릉 관측지점에서 발생한 고파 이벤트의 특성 들이다.

돌연고파의 강도를 나타내는 두 변수, $\Delta H / \Delta t$ 와 $\Delta\left(H^{2} L\right) / \Delta t$ 를 비교해 보았을 때 대부분의 사건에서 $\Delta\left(H^{2} L\right) / \Delta t$ 의 순위 가 $\Delta H / \Delta t$ 의 순위보다 더 높은 순위에 위치해 있음을 알 수 있다. 따라서 파고의 변화율을 나타내는 $\Delta H / \Delta t$ 보다 파랑 에 너지의 변화율을 나타내는 $\Delta\left(H^{2} L\right) / \Delta t$ 가 돌연고파의 강도를 나타내는 데 더 적합한 변수로 볼 수 있다. 또한 $\Delta\left(H^{2} L\right) / \Delta t$ 가 가장 큰 값을 갖는 2005 년 10 월 21일과 2006년 10 월 23일에 발생한 사건들을 보면, 인명피해뿐만 아니라 넓은 지역에 걸쳐 
Table 2. Marine accidents and/or property damage along the coast of Gangwon-do Province and Gyeongsangbuk-do Province (from Geosystem Research, 2015).

\begin{tabular}{|c|c|c|c|c|c|}
\hline \multicolumn{2}{|c|}{ Date } & Area & Specific area & $\begin{array}{l}\text { Life damage } \\
\text { (Death) }\end{array}$ & Remarks \\
\hline \multirow{7}{*}{2005} & 10.21 & Pohang & Ship at $7 \mathrm{~km}$ offshore & 14(9) & One ship sank, nine crew members disappeared \\
\hline & 10.22 & Pohang & Imgok-ri breakwater & $2(2)$ & Two children killed \\
\hline & 10.22 & Donghae & Daejin Port & $3(0)$ & Breakwater damage \\
\hline & 10.22 & Donghae & Cheongok Port & $3(0)$ & Breakwater damage \\
\hline & 10.22 & Gangneung & Jumunjin Port breakwater & $1(1)$ & One tourist killed \\
\hline & 10.23 & Sokcho & Yeongrang-dong & - & Three houses partially destroyed, road damage \\
\hline & 10.23 & Sokcho & Jangsa Port & - & Two ships sank \\
\hline \multirow{5}{*}{2006} & 10.08 & Pohang & Yangpo Port breakwater & $13(2)$ & Eleven tourists injured, two killed \\
\hline & 10.09 & Ulleung & Jeodong Inner Port breakwater & $1(1)$ & One tourist killed \\
\hline & 10.23 & East Sea & Entire area & - & 110 ships, 270 houses damaged \\
\hline & 10.23 & Sokcho & Ship at $100 \mathrm{~km}$ offshore & $7(4)$ & One ship sank \\
\hline & 10.23 & Goseong & Bongpo Port breakwater & $4(1)$ & Four tourists swept away, one killed \\
\hline 2007 & 10.28 & Sokcho & Seashore rocks off Yeonggeum-jeong & $3(1)$ & One tourist killed, two injured \\
\hline 2008 & 2.24 & Gangneung & Anmok Port & 18(3) & Three tourists killed \\
\hline \multirow{2}{*}{2009} & 1.10 & Gangneung & Jumunjin Port breakwater & $1(1)$ & One tourist killed \\
\hline & 1.13 & Gangneung & Jumunjin Port north breakwater & $5(3)$ & Three out of five tourists killed \\
\hline \multirow{3}{*}{2012} & 1.1 & Pohang & Seashore rocks off Youngam-ri & $2(0)$ & All rescued \\
\hline & 1.20 & Samcheok & $\begin{array}{c}\text { Seashore rocks at Namaemul, } \\
\text { Wondeok-eup }\end{array}$ & 2(1) & One angler killed, one rescued \\
\hline & 11.20 & Gangneung & Namhangjin & $4(0)$ & One barge damaged, rescue of human lives \\
\hline
\end{tabular}

Table 3. Characteristics of $\Delta H / \Delta t$ and $\Delta\left(H^{2} L\right) / \Delta \mathrm{t}$ at Gangneung wave station.

\begin{tabular}{ccccc}
\hline \hline \multirow{2}{*}{ Date } & \multicolumn{3}{c}{$\Delta H / \Delta t$} & \multicolumn{2}{c}{$\Delta\left(H^{2} L\right) / \Delta t$} \\
\cline { 2 - 5 } & Value $(\mathrm{m} / \mathrm{hr})$ & Rank (Percent) & Value $\left(\mathrm{m}^{3} / \mathrm{hr}\right)$ & $1(0.49)$ \\
\hline $2005 / 10 / 21$ & 0.807 & $1(0.48)$ & 523.6 & $2(0.98)$ \\
$2006 / 10 / 23$ & 0.367 & $3(1.44)$ & 353.2 & $73(35.4)$ \\
$2007 / 10 / 29$ & 0.128 & $32(15.3)$ & 38.6 & $67(32.5)$ \\
$2008 / 02 / 24$ & 0.080 & $65(31.2)$ & 40.7 & $22(10.7)$ \\
$2009 / 01 / 09$ & 0.052 & $89(42.8)$ & 98.2 & $70(34.0)$ \\
$2012 / 01 / 22$ & 0.012 & $197(94.7)$ & 39.4 & $47(22.9)$ \\
$2012 / 11 / 20$ & 0.075 & $71(34.1)$ & 59.0 & \\
\hline
\end{tabular}

상당한 재산피해가 발생했음을 알 수 있다. 따라서 $\Delta\left(H^{2} L\right) / \Delta t$ 의 값이 사건의 규모와 비례하는 것을 알 수 있다.

한편, 강릉 및 왕돌초 지역의 파랑 관측자료에 대하여 최 솟값 비교간격을 60 시간으로 하여 $H^{2} L$ 에 대한 이벤트를 생 성한 결과, 각각 206 개와 155 개의 이벤트가 생성되었다. 각 지역에서 생성된 이벤트에서 돌연고파의 강도를 나타내는 변 수인 $\Delta\left(H^{2} L\right) / \Delta t$ 또한 206개와 155 개가 생성되었다. 생성된 총 361개의 $\Delta\left(H^{2} L\right) / \Delta t$ 에 대하여 누적백분율 곡선을 그려 본 결과, Fig. 6과 같이 누적백분율이 급격히 증가하다가 대 략 상위 $20 \%$ 범위 안에서 완만하게 증가하는 특성을 보인다. 따라서 $\Delta\left(H^{2} L\right) / \Delta t$ 의 상위 $20 \%$ 값인 $88.6 \mathrm{~m}^{3} / \mathrm{hr}$ 을 임의의 돌연고파의 기준으로 설정하고, $\Delta\left(H^{2} L\right) / \Delta t$ 가 $88.6 \mathrm{~m}^{3} / \mathrm{hr}$ 이

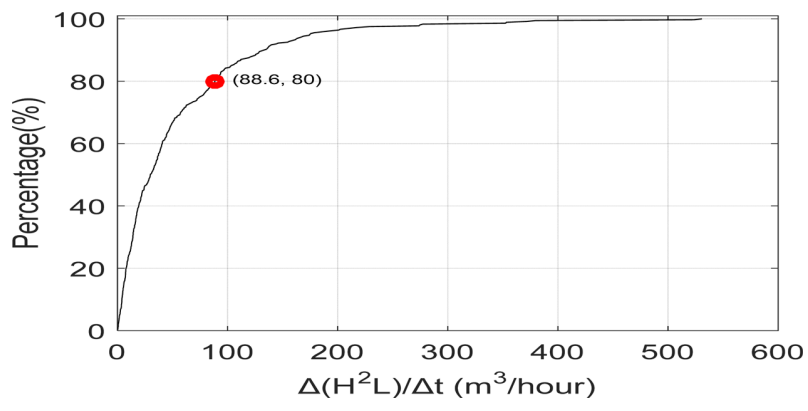

Fig. 6. Cumulative percentage curve of $\Delta\left(H^{2} L\right) / \Delta t$.

상인 이벤트들과 강원도와 경상북도 연안의 해난 사고 및 피 해 현황 자료와 비교해 보았다. 
Table 4. Comparison of sudden high wave events of $\Delta\left(H^{2} L\right) / \Delta t \geq 88.6 \mathrm{~m}^{3} / \mathrm{hr}$ and marine accidents.

\begin{tabular}{|c|c|c|c|c|c|}
\hline \multicolumn{2}{|c|}{ Gangneung } & \multicolumn{2}{|c|}{ Wangdolcho } & \multicolumn{2}{|c|}{ Accident } \\
\hline Period & $\Delta\left(H^{2} L\right) / \Delta t\left(\mathrm{~m}^{3} / \mathrm{hr}\right)$ & Period & $\Delta\left(H^{2} L\right) / \Delta t\left(\mathrm{~m}^{3} / \mathrm{hr}\right)$ & Date & Area \\
\hline \multirow{7}{*}{$\begin{array}{c}2005 / 10 / 21 \quad 17: 30 \\
-2005 / 10 / 24 \quad 06: 30\end{array}$} & \multirow{7}{*}{523.6} & \multirow{7}{*}{$\begin{array}{c}2005 / 10 / 2121: 00 \\
-2005 / 10 / 2418: 30\end{array}$} & \multirow{7}{*}{128.4} & $2005 / 10 / 21$ & Pohang \\
\hline & & & & $2005 / 10 / 22$ & Pohang \\
\hline & & & & $2005 / 10 / 22$ & Donghae \\
\hline & & & & $2005 / 10 / 22$ & Donghae \\
\hline & & & & $2005 / 10 / 22$ & Gangneung \\
\hline & & & & $2005 / 10 / 23$ & Sokcho \\
\hline & & & & $2005 / 10 / 23$ & Sokcho \\
\hline \multirow{2}{*}{$\begin{array}{c}2006 / 10 / 1121: 30 \\
-2006 / 10 / 12 \quad 15: 00\end{array}$} & \multirow{2}{*}{79.1} & \multirow{2}{*}{$\begin{array}{c}2006 / 10 / 1201: 30 \\
-2006 / 10 / 12 \quad 20: 00\end{array}$} & \multirow{2}{*}{47.7} & $2006 / 10 / 08$ & Pohang \\
\hline & & & & $2006 / 10 / 09$ & Ulleng \\
\hline \multirow{3}{*}{$\begin{array}{c}2006 / 10 / 22 \text { 21:00 } \\
-2006 / 10 / 2518: 00\end{array}$} & \multirow{3}{*}{353.2} & \multirow{3}{*}{$\begin{array}{c}2006 / 10 / 2303: 00 \\
-2006 / 10 / 2523: 30\end{array}$} & \multirow{3}{*}{274.8} & $2006 / 10 / 23$ & Entire East Sea \\
\hline & & & & $2006 / 10 / 23$ & Sokcho \\
\hline & & & & $2006 / 10 / 23$ & Goseong \\
\hline $\begin{array}{c}2008 / 02 / 2304: 30 \\
-2008 / 02 / 25 \quad 20: 00\end{array}$ & 40.7 & $\begin{array}{c}2008 / 02 / 2306: 30 \\
-2008 / 02 / 25 \quad 18: 00\end{array}$ & 371.6 & $2008 / 02 / 24$ & Gnagneung \\
\hline \multirow{2}{*}{$\begin{array}{c}2009 / 01 / 09 \quad 01: 30 \\
-2009 / 01 / 11 \quad 08: 30\end{array}$} & \multirow{2}{*}{98.2} & \multirow{2}{*}{$\begin{array}{c}2009 / 01 / 09 \quad 07: 30 \\
-2009 / 01 / 11 \quad 19: 00\end{array}$} & \multirow{2}{*}{146.1} & $2009 / 01 / 10$ & Gnagneung \\
\hline & & & & $2009 / 01 / 13$ & Gnagneung \\
\hline $\begin{array}{c}2012 / 01 / 01 \quad 18: 00 \\
-2012 / 01 / 03 \quad 10: 30\end{array}$ & 112.1 & $\begin{array}{c}2012 / 01 / 0121: 30 \\
-2012 / 01 / 2412: 00\end{array}$ & 530.8 & $2012 / 01 / 01$ & Pohang \\
\hline $\begin{array}{c}2012 / 01 / 12 \quad 21: 00 \\
-2012 / 01 / 23 \quad 20: 30\end{array}$ & 39.4 & $\begin{array}{c}2012 / 01 / 2209: 30 \\
-2012 / 01 / 24 \quad 12: 00\end{array}$ & 108.7 & $2012 / 01 / 20$ & Samchoek \\
\hline $\begin{array}{c}2012 / 11 / 20 \quad 05: 30 \\
-2012 / 11 / 21 \quad 12: 30\end{array}$ & 59.0 & $\begin{array}{c}2012 / 11 / 2306: 30 \\
-2012 / 11 / 24 \quad 15: 30\end{array}$ & 84.8 & $2012 / 11 / 20$ & Gnagneung \\
\hline
\end{tabular}

Table 5. Precipitation and maximum wind speed during marine accident and/or property damage due to sudden high waves.

\begin{tabular}{|c|c|c|c|c|c|}
\hline & Date & Area & Specific area & Precipitation (mm) & Max wind speed $(\mathrm{m} / \mathrm{s})$ \\
\hline \multirow{7}{*}{2005} & $10 / 21$ & Pohang & Ship at $7 \mathrm{~km}$ offshore & 0.4 & 8.3 \\
\hline & $10 / 22$ & Pohang & Imgok-ri breakwater & 2.0 & 3.6 \\
\hline & $10 / 22$ & Donghae & Daejin Port & 4.5 & 10.7 \\
\hline & $10 / 22$ & Donghae & Cheongok Port & 4.5 & 10.7 \\
\hline & $10 / 22$ & Gangneung & Jumunjin Port breakwater & 1.5 & 6.9 \\
\hline & $10 / 23$ & Sokcho & Yeongrang-dong & - & 4.8 \\
\hline & $10 / 23$ & Sokcho & Jangsa Port & - & 4.8 \\
\hline \multirow{3}{*}{2006} & $10 / 23$ & East Sea & Entire area & 232 & 30.5 \\
\hline & $10 / 23$ & Sokcho & Ship at $100 \mathrm{~km}$ offshore & 232 & 30.5 \\
\hline & $10 / 23$ & Goseong & Bongpo Port breakwater & 232 & 30.5 \\
\hline 2008 & $2 / 24$ & Gangneung & Anmok Port & - & 5.2 \\
\hline 2009 & $1 / 10$ & Gangneung & Jumunjin Port breakwater & - & 8.1 \\
\hline 2012 & $1 / 1$ & Pohang & Seashore rocks off Youngam-ri & - & 4.9 \\
\hline
\end{tabular}

$\Delta\left(H^{2} L\right) / \Delta t$ 가 $88.6 \mathrm{~m}^{3} / \mathrm{hr}$ 이상인 이벤트들과 Table 2 의 강원도와 경상북도에서 발생한 사고 및 피해를 비교한 결과 를 Table 4에 정리하였다. 돌연고파 이벤트에 대하여 시작 시 간부터 종료 시간(유의파고가 $1.25 \mathrm{~m}$ 이하가 되는 시간)까지 의 기간을 표시하여, 사고 발생 일자가 돌연고파 기간 내에 해 당하는 지를 검토하였다. 이 표에서 $\Delta\left(H^{2} L\right) / \Delta t$ 가 $88.6 \mathrm{~m}^{3} / \mathrm{hr}$
이하인 경우와 사고 발생 일자가 돌연고파 기간 내에 포함되 지 않는 경우는 표의 칸을 음영으로 처리하였다. 그 결과 총 18 개 사고 기록 중 13 개의 사고가 $\Delta\left(H^{2} L\right) / \Delta t$ 가 $88.6 \mathrm{~m}^{3} / \mathrm{hr}$ 이상인 돌연고파 기간 중에 발생하였음을 확인하였다. 나머 지 5 건의 사고는 다른 원인으로 인하여 발생한 것으로 추정 된다. 결론적으로 Table 2에 정리한 사고 기록 중 Table 4에 
포함되지 않은 것들과 위에서 설명한 돌연고파 기간을 벗어 나서 발생한 5 건의 사고들은 단순 고파 또는 다른 원인에 의 한 사고로 간주할 수 있다.

본 연구에서 분석한 총 고파 이벤트가 361 개인데 $\Delta\left(H^{2} L\right) / \Delta t$ 의 상위 $20 \%$ 값인 $88.6 \mathrm{~m}^{3} / \mathrm{hr}$ 을 돌연고파의 기준으로 잡았 기 때문에 이 기준을 만족시키는 이벤트의 갯수는 72 개이다 . 하지만 Table 4에서 보듯이 돌연고파의 기준을 만족시키면 서 해상 사고를 발생시킨 이벤트는 9 개에 불과하다. 나머지 63 개의 돌연고파 이벤트에는 사고가 발생하지 않았음을 의미 한다. 따라서 돌연고파가 발생하더라도 대부분의 경우에는 사 고 없이 지나가게 됨을 알 수 있다.

마지막으로, 악천후로 인한 사고와 돌연고파에 의한 사고 와의 구분을 위하여 Table 4의 돌연고파에 의한 사고가 발생 한 날에 해당 장소에서의 강수량과 평균 풍속을 Table 5 에 정 리하였다. 24시간 동안의 강수량이 $80 \mathrm{~mm}$ 이상일 때 발표되 는 호우경보와, 해상에서 10 분 동안의 평균 풍속이 $14 \mathrm{~m} / \mathrm{s}$ 이 상인 상태가 3 시간 이상 지속될 때 발표되는 풍랑경보에 해 당되는 경우는 2006년 10 월 23일의 돌연고파 이벤트뿐이었 다. 이 날에는 악천후와 돌연고파가 동시에 발생한 것으로 판 단된다. 나머지 사고들은 악천후와 상관 없이 돌연고파만에 의한 사고라고 말할 수 있다. 따라서 Table 5의 사고들은 모 두 돌연고파에 의한 사고라고 결론지을 수 있다.

\section{5. 결 론}

우리나라 동해안에서 겨울철에 갑자기 발생하는 장주기 고 파랑 현상에 대해서 기존의 너울성 고파라는 용어는 파고가 크고 주기가 길다는 특징은 나타내지만 현상의 돌발성을 나 타내지는 못한다. 또한 너울성 고파에 대한 기존의 기준은 파 고와 주기만을 포함하기 때문에 이러한 현상이 얼마나 갑자 기 발생하는 지를 표현하지 못한다. 이러한 문제점을 해결하 기 위하여 본 연구에서는 이 현상을 돌연고파로 정의하고, 돌 연고파의 가장 중요한 특징 중 하나인 돌발성을 잘 표현할 수 있는 기준을 제시하였다. 돌연고파의 파고, 주기 (또는 파장) 및 발생 소요 시간 등을 나타낼 수 있는 변수로 $\Delta\left(H^{2} L\right) / \Delta t$ 를 선 정하고, 2005년부터 2012년 사이에 강원도와 경상북도의 연 안에서 발생한 인명 및 재산 피해 현황과 강릉과 왕돌초에서 관측된 파랑 자료를 비교하여 $\Delta\left(H^{2} L\right) / \Delta t$ 의 상위 $20 \%$ 값인 $\Delta\left(H^{2} L\right) / \Delta t \geq 88.6 \mathrm{~m}^{3} / \mathrm{hr}$ 를 돌연고파의 기준으로 제시하였다. 그러나 이 기준은 임시적으로 제시한 기준으로 추후에 더 많 은 자료를 이용하여 탄력적으로 조정할 수 있으며, 본 연구 에서 조사하지 않은 지역의 피해 현황과 파랑 자료를 이용하 면 더 명확하게 사고를 포괄할 수 있는 기준을 제시할 수 있 을 것이다. 또한, 본 연구에서 제시한 기준을 파랑예보 자료 와 함께 사용하면 돌연고파의 예·경보 수단으로 사용될 수 있을 것이다.

\section{감사의 글}

본 연구는 해양수산부 해양과학조사 및 예보기술개발사업 의 일환인 “연안 이상현상(이상고파, 이안류) 발생원인 규명 및 대응체계 구축(No. 20140057)"의 지원으로 수행되었습니 다. 본 연구는 서울대학교 공학연구원에서 수행되었습니다.

\section{References}

Geosystem Research Corporation (2015). Yearly Report of the Project of Investigation of Large Swell Waves and Rip Currents and Development of the Disaster Response System (in Korean).

Jeong, W.M. and Oh, S.H. (2009). Abnormally high swells occurred on the East Coast in recent several years. Proceedings of 2009 Joint Conference of Korean Association of Ocean Science and Technology Societies, 2119-2122 (in Korean).

Jeong, W.M., Oh, S.H. and Lee, D.Y. (2007). Abnormally high waves on the East Coast. Journal of Korean Society of Coastal and Ocean Engineers, 19(4), 295-302 (in Korean).

Jeong, W.M., Oh, S.H., Ryu, K.H. and Kim, T.I. (2008). Characteristics of abnormally high waves on the East Coast, February 2008. Proceedings of 2008 Joint Conference of Korean Association of Ocean Science and Technology Societies, 2480-2483 (in Korean).

Korea Meteorological Administration (2005-2012). Monthly Weather Report.

Kim, T.R. and Lee, D.Y. (2008). Wavelet analysis of swells in the East Sea. Journal of Korean Society of Coastal and Ocean Engineers, 20(6), 583-588 (in Korean).

Lee, H.S., Kim, K.O., Yamashita, T., Komaguchi, T. and Mishima, T. (2010). Abnormal storm waves in the winter East/ Japan Sea: generation process and hindcasting using an atmosphere-wind wave modelling system. Natural Hazards and Earth System Sciences, 10, 773-792.

Nagai, T., Hiraishi, T., Kawai, H., Kawaguchi, K., Nihei, A. and Ohkama, T. (2009). Characteristics of Yorimawari-nami, peculiar Japan-Sea low frequency swell, observed by NOWPHAS seabed wave gauge network. Proceedings of 19th International Offshore and Polar Engineering Conference, Osaka, Japan, 940-945.

Oh, S.H., Jeong, W.M., Lee, D.Y. and Kim, S.I. (2010). Analysis of the reason for occurrence of large-height swell-like waves in the East Coast of Korea, Journal of Korean Society of Coastal and Ocean Engineers, 22(2), 101-111 (in Korean).

World of Earth Science (2003). Douglas sea scale. http:// www.encyclopedia.com/doc/1G2-3437800174.html.

Received 19 February, 2016

Revised 13 April, 2016

Accepted 1 May, 2016 